\title{
POBREZA MULTIDIMENSIONAL NA AMAZÔNIA LEGAL: UMA ANÁLISE SOBRE O ÍNDICE DE DESENVOLVIMENTO DA FAMÍLIA (IDF)
}

\author{
Luciana Cristina Romeu Sousa ${ }^{1}$ \\ Ricardo Bruno Nascimento Santos ${ }^{2}$ \\ David Silva Pereira Sousa ${ }^{3}$
}

\begin{abstract}
RESUMO
Com base na abordagem das capacitações o objetivo deste artigo será realizar um estudo sobre pobreza e desenvolvimento nos municípios da Amazônia Legal, através da metodologia de mensuração de índice sintético, chamado de Índice de Desenvolvimento da Família (IDF). Os resultados da pesquisa, no que diz respeito aos dados do IDF, mostraram que a região ainda apresenta algumas limitações quanto ao seu nível de desenvolvimento, pois apenas uma pequena parcela dos municípios encontra-se em condições de médio nível de desenvolvimento. No entanto, $80 \%$ os municípios apresentaram uma relativa melhora em seus indicadores entre os anos 2000 e 2010.
\end{abstract}

Palavras-chave: Abordagem das Capacitações. Índice de Desenvolvimento da Família (IDF). Amazônia Legal.

\section{POVERTY MULTIDIMENSIONAL IN AMAZÔNIA LEGAL: AN ANALYSIS OF FAMILY DEVELOPMENT INDEX (IDF)}

\begin{abstract}
Based on the capabilities approach the purpose of this article is to conduct a study on poverty and development in the municipalities of the Amazônia Legal, through the synthetic index measurement methodology, called the Family Development Index (FDI). The survey results, with regard to IDF data, showed that the region still has some limitations as to their level of development, since only a small portion of the municipalities is able to average level of development. However, $80 \%$ of the municipalities showed a relative improvement in their indicators between 2000 and 2010.
\end{abstract}

Keywords: the Capability Approach. The Family Development Index (FDI). Amazônia Legal.

\footnotetext{
${ }^{1}$ Administradora (Centro Universitário do Pará - CESUPA), Economista (UFPA), Especialista em Economia Regional e Meio Ambiente pelo Programa de Pós-Graduação em Economia (PPGE/UFPA), Mestra em Economia (PPGE/UFPA) e Doutoranda em Economia (PPGE/UFPA). Universidade Federal do Pará - UFPA. Pará. Brasil. E-mail: luci_romeu@yahoo.com.br

${ }^{2}$ Doutor em Economia Aplicada pela Universidade Federal de Viçosa (UFV - MG). Professor Adjunto I na UFPA. Universidade Federal do Pará - UFPA. Pará. Brasil. E-mail: rbns@ gmail.com

${ }^{3}$ Economista (UFPA), Mestre em Economia (PPGE/UFPA) e Doutorando em Economia (PPGE/UFPA). Universidade Federal do Pará - UFPA. Pará. Brasil. E-mail: d_sps@ hotmail.com
} 


\section{INTRODUÇÃO}

A partir da década de 1950 a necessidade de se mensurar o desenvolvimento econômico de países levou a profundas discussões ao significado de desenvolvimento e consequentemente a novas pesquisas sobre o tema. Tais pesquisas apresentaram características essencialmente qualitativas na sua abordagem e metodologia de mensuração do nível de desenvolvimento de um país, a partir da quantificação de seu nível de pobreza.

Neste sentido, as discussões sobre o tema iniciam na abordagem unidimensional da pobreza, na qual a renda monetária é a variável que determina a pobreza e o nível de desenvolvimento pessoal ou regional. Entretanto, embora a insuficiência de renda seja um importante indicador de pobreza, ela sem dúvida não é o único possível.

Neste sentindo, destaca-se a "Abordagem das Capacitações” de Amartya Sen de 2001 (uma ramificação da abordagem multidimensional). Essa abordagem consiste num amplo enfoque de bem-estar e pobreza, pois nela buscam-se entender o bem-estar e a pobreza como expansão da capacitação humana.

Com base na abordagem das capacitações foram iniciadas tentativas de mensuração do desenvolvimento humano e pobreza na sua multidimensionalidade. O Programa das Nações Unidas Para o Desenvolvimento - UNDP em 1990 lançou o Índice de Desenvolvimento Humano - IDH. Em 2003 Ricardo Paes de Barros junto com Mirela de Carvalho e Samuel Franco lançaram o Índice de Desenvolvimento da Família - IDF.

Dessa forma, o objetivo do trabalho é, através da estimação do IDF, descrever o perfil socioeconômico e analisar o nível de desenvolvimento dos municípios da Amazônia Legal nos anos de 2000 e 2010. É importante destacar que os dados foram extraídos da base dos microdados dos Censos Demográficos 2000 e 2010, por isso o período escolhido. Os objetivos do trabalho foram traçados partindo da hipótese de que o IDF é o um indicador de qualidade para medir o nível de desenvolvimento do objeto de estudo.

A razão de se escolher a Amazônia Legal como objeto de estudo se dá devido à mesma ser uma região de característica ímpar em todo Brasil, pois possui um processo histórico de ocupação diferente de qualquer outra região do país, além de possuir uma rica diversidade em recursos naturais é uma grande fonte de matéria-prima para todas as partes do país e do mundo. E a razão de se escolher o IDF para se medir o desenvolvimento humano dos municípios da Amazônia Legal se dá por considerar o mesmo mais eficiente do que o IDH devido sua metodologia de cálculo. O IDF apresenta resultados que condizem mais com a verdadeira realidade da região, pois o mesmo é facilmente desagregável, podendo assim oferecer dados mais exatos.

Dessa forma, além dessa introdução o trabalho está dividido da seguinte forma: i) levantamento bibliográfico acerca da abordagem multidimensional da pobreza; ii) metodologia; iii) apresentação do IDF, suas dimensões e metodologia de cálculo; iv) os resultados da pesquisa e; v) a conclusão desse trabalho. 


\section{DA ABORDAGEM UNIDIMENSIONAL À MULTIDIMENSIONAL DA POBREZA}

A abordagem unidimensional da pobreza, apresenta uma noção tradicional da mesma, onde relaciona apenas bem-estar com utilidades. Ou seja, o conceito de pobreza relaciona-se apenas a renda monetária: pobres são aqueles que não têm renda suficiente ou consumo acima do limite adequado para sua subsistência física (SEN, 1981).

Esta abordagem apresenta algumas dificuldades, pois o bem-estar sendo considerado satisfação de preferências não garante que o agente estará sempre mais feliz ao satisfazer uma necessidade, além disso, essa abordagem interpreta as necessidades humanas como predominantemente físicas, não deixando claro se a preocupação é com as utilidades totais ou com a felicidade média. Porém apesar das dificuldades a abordagem permanece como uma visão ética extremamente poderosa, principalmente quando a preocupação são questões de ordem pública (HAUSMAN e MCPHERSON, 2006).

A abordagem unidimensional envolve a definição e uso de linha de pobreza que pode ser entendida como: o custo monetário para uma pessoa em determinado lugar e tempo atingir o seu bem-estar, ou seja, as pessoas que ficarem abaixo deste limite mínimo para satisfação de suas necessidades são consideradas pobres, e as que atingem a linha não são (RAVALLION, 1992 e 1998).

Ravallion (1992) considera quatro tipos de linhas de pobreza: absoluta, relativa, subjetiva e dual. A linha de pobreza absoluta se obtém ao estimar-se o custo de bens que satisfarão as necessidades básicas de consumo. Nesta linha os indivíduos podem ser considerados absolutamente pobres ou indigentes ${ }^{4}$.

A linha de pobreza relativa considera as necessidades a serem satisfeita de acordo com o modo de vida predominante na sociedade em questão. Esta linha está relacionada ao conceito de pobreza como necessidades insatisfeitas, considerando como pobres aqueles que não possuem acesso aos recursos físicos que normalmente são necessários para levar uma vida digna em razão da falta de renda monetária, tais como: mínimo de alimentos, roupas, moradia, serviços essenciais como água potável, transporte público, saúde, educação, saneamento e acesso a cultura (ROCHA, 2006; CODES, 2008).

A linha de pobreza dual consiste na combinação simples das duas linhas de pobrezas acima citadas, para definir uma linha de pobreza múltipla de forma a fazer comparações de pobrezas. E a linha de pobreza subjetiva são inerentes aos julgamentos subjetivos feitos pelas pessoas sobre o que constitui um padrão de vida mínimo aceitável em uma sociedade em particular (RAVALLION, 1992).

Desta forma, depois de definida a linha de pobreza nessa abordagem, pode-se calcular medidas de pobreza, pois dizer apenas que a pobreza existe não é suficiente, portanto, é necessário saber o quanto ela existe, para assim serem feitas análises políticas.

\footnotetext{
${ }^{4}$ A linha de indigência considera as pessoas que conseguem adquirir, com sua renda monetária, uma cesta de alimentos com a quantidade de calorias mínimas para sua sobrevivência (LOUREIRO e SULIANO, 2009).
} 
As medidas unidimensionais da pobreza foram desenvolvidas e aprimoradas com o tempo. E apesar dessas mudanças, com o passar do tempo às discussões sobre as melhores medidas para mensuração da pobreza começaram a considerar limitações nessa abordagem, pois a renda monetária não é o único indicador para existência da pobreza, existem outras privações que influenciam a existência da pobreza como a privação da educação, da saúde, de moradia, de oportunidades de trabalho, dentre outras.

Segundo Sen (2000) cita três desvantagens da abordagem unidimensional: i) o cálculo não considera as desigualdades na distribuição das felicidades; ii) não atribui importância a reivindicações de direitos, liberdades e outras considerações desvinculadas a utilidade; e iii) a abordagem não é muito sólida e pode ser influenciada por condicionamento mental e atitudes adaptativas.

Sen acredita que o que podemos fazer ou realizar não depende apenas de nossas rendas, mas também das características físicas e sociais que afetam nossas vidas e fazem de nós o que somos (SEN, 2001). Neste sentido, Sen identifica cinco fontes distintas de variações entre o bem-estar e a liberdade: i) heterogeneidade pessoais: as pessoas diferem em gênero, idade, propensão a doenças, incapacidade, etc., isso resulta em diferentes necessidades; ii) diversidades ambientais: variações climáticas e ambientais podem influenciar no que uma pessoa obtém de determinado nível de renda; iii) variações no clima social: a conversão de rendas e recursos sociais em qualidade de vida pode ser influenciada por condições sociais como oferta de serviços públicos, educação, saúde, saneamento básico, infraestrutura, presença de violência, etc.; iv) diferença de perspectivas relativas: as necessidades de cada indivíduo pode variar de acordo com as convenções e costumes da comunidade em que vive; e v) distribuição na família: o bem-estar ou liberdade dos indivíduos da família depende do modo como a renda é distribuída e usada na promoção dos interesses e objetivos familiares.

Desse modo, Sen (2001) conclui que a abordagem utilitarista ou unidimensional limita as comparações interpessoais para a avaliação social a realizações, e identifica as realizações como as utilidades realizadas. Diante disso, pode-se perceber claramente a diferença dos dois enfoques, pois não se pode negar que o crescimento econômico é importante para superação da pobreza, já que o mesmo permite as pessoas adquirirem mais alimento, roupas e bens, no entanto a riqueza ou crescimento não são desejáveis por si mesmas, mas sim por ser um meio de levar as pessoas ao tipo de vida que elas valorizam.

Neste sentido houve uma mudança no enfoque da pobreza de privação absoluta para privação relativa. No qual a primeira relaciona a pobreza somente a restrição de renda e a segunda está associada ao estilo de vida predominante em cada sociedade, ou seja, está relacionada não apenas as necessidades de sobrevivência, mas também ao comportamento de uma sociedade, por exemplo, em uma sociedade onde as necessidades primárias já foram satisfeitas seria difícil distinguir os pobres dos não pobres, dessa forma, seria levado em consideração outras variáveis que não seja somente a renda, como a educação, o salário, a qualificação profissional, dentre outras.

É neste sentido que Sen propõe a Abordagem das Capacitações como uma forma multidimensional de analisar os processos de desenvolvimento e consequentemente a pobreza.

DRd - Desenvolvimento Regional em debate (ISSNe 2237-9029) 


\subsection{ABORDAGEM DAS CAPACITAÇÕES}

Na perspectiva da abordagem das capacitações proposta por Sen, o desenvolvimento é concebido como um processo que garante a expansão das oportunidades das pessoas em levar a vida que elas têm razão de valorizar (SEN, 2000).

Sen (2000) faz uma crítica às abordagens tradicionais de desenvolvimento, que desconsideram a multidimensionalidade da pobreza e dos aspectos que a geram. Para o autor, a lacuna entre a perspectiva da concentração exclusiva na riqueza econômica e a perspectiva em um enfoque mais amplo sobre a vida que as pessoas desejam levar é a questão fundamental na conceituação do desenvolvimento.

Segundo Sen, uma concepção adequada de desenvolvimento deve ultrapassar análise da renda, do crescimento do PIB (Produto Interno Bruto) ou PNB (Produto Nacional Bruto) e das necessidades básicas, para relacionar-se com a possibilidade de melhora de vida, através da expansão das liberdades para que se possa viver do modo como se deseja. A expansão das liberdades permite que os indivíduos sejam seres sociais mais completos.

Para Sen a abordagem de desenvolvimento inclui participação, bem-estar humano e liberdade como fator central de desenvolvimento. A partir dessa abordagem busca-se avaliar como as pessoas expandem suas capacitações. As capacitações, para o autor, são aquilo que as pessoas são capazes de fazer e ser, ou seja, suas liberdades para apreciar valores de ser e de fazer.

Dessa forma, Sen (2000) vê o desenvolvimento como um processo de expansão das liberdades reais que as pessoas desfrutam. A abordagem do desenvolvimento através da liberdade, obtida pela expansão das capacitações, tem implicações no processo de desenvolvimento realmente igualitário e no respeito à vontade das pessoas. Nessa abordagem, a expansão da liberdade é considerada um fim primordial e o principal meio para o desenvolvimento.

Segundo a Abordagem das Capacitações, o processo de desenvolvimento, admitido como uma melhoria da qualidade de vida das pessoas, só pode ser "documentado" a partir da identificação de um aumento das oportunidades de escolhas dos agentes sociais. O acesso a mais oportunidades de escolha significaria ao indivíduo uma possibilidade de incrementar suas capacitações.

No entanto, Sen (2000) considera importante distinguir o meio e o fim do desenvolvimento, isto serve como base para a abordagem das capacitações. Segundo Sen (2000) a primeira diferença é que a prosperidade econômica é apenas um dos meios para enriquecer a vida das pessoas, portanto é errado atribuir a ela o estatuto de objetivo a alcançar, a segunda diferença é que mesmo como um meio, o mero aumento da riqueza econômica pode ser ineficaz na consecução de fins realmente valiosos.

Partindo dessa diferenciação fundamental entre meios e fins para análise e compreensão do processo de desenvolvimento, o autor procura apresentar alguns conceitos que representam a base teórica para essa abordagem das capacitações. O conceito fundamental da abordagem é o de funcionamentos. Este conceito está associado à 
atividades/ações (por exemplo, comer, ler, escrever) ou a estados de existência (por exemplo, estar bem nutrido, não estar exposto a doenças evitáveis) (SEN, 2001).

As alternativas que uma pessoa dispõe para realizar os funcionamentos que ela tem razão de valorizar formam o conjunto de suas capacidades (conjunto capacitário). Esse conceito está associado, então, às oportunidades de realização dos funcionamentos, se o conjunto capacitário aumenta, o processo de desenvolvimento pode ser caracterizado, ou seja, alguém com mais oportunidades teria adquirido mais liberdade para tomar decisões. Considerando que a pessoa é o agente que toma a decisão, Sen tira o agente social da posição passiva de beneficiário de processos de desenvolvimento.

Ao mesmo tempo em que a abordagem das capacitações exige do processo de desenvolvimento um aumento nas possibilidades de escolha dos agentes, ela nos apresenta uma noção relacionada às condições de realização das escolhas por determinados funcionamentos - os entitulamentos.

Entitulamentos refere-se ao conjunto alternativo de cestas de bens que uma pessoa pode ordenar em uma sociedade através de canais legais e usando a sua totalidade de direitos e oportunidades, eles são estabelecidos por ordenamentos legais, político e econômico (SEN, 2001, p. 235). Além disso, é preciso estar atento durante a análise aos valores sociais envolvidos, pois os entitulamentos e funcionamentos devem refletir opções e escolhas que cada agente social tem razão para valorizar.

A análise está associada a dois níveis de informação: as opções dadas aos indivíduos e a possibilidade que, dadas essas opções, os agentes têm de realizar suas escolhas. Certamente existem muitas das questões de método envolvidas em "escolhas" sob responsabilidade do pesquisador, como estas, ainda precisam ser resolvidas na abordagem. Entretanto, Sen (2000) chama a atenção de que é preciso tomar decisões, mesmo àquelas que poderiam ser discutidas no campo da ética.

A noção de desenvolvimento como expansão de capacidades coloca ênfase na dinâmica das relações sociais. Essa questão é essencial no sentido de determinar que tipo de medida social pode ser mais adequada, para a expansão das capacitações (ou eliminação da retenção de algumas capacitações, como por exemplo, na análise de situações de pobreza).

\section{METODOLOGIA}

A metodologia utilizada será a de índices sintéticos, e para o desenvolvimento do IDF foram utilizadas como ferramentas econométricas, em primeiro momento, o software R, para a extração dos dados da base dos Microdados dos Censos Demográficos 2000 e 2010. Após extrair os dados e agregá-los por famílias e municípios, foi utilizado o software Stata 13 para geração do índice final.

Na sua construção do IDF, optou-se por tratar todas as dimensões e seus componentes de forma simétrica, mais especificamente atribuindo o mesmo peso: i) a todos os indicadores

DRd - Desenvolvimento Regional em debate (ISSNe 2237-9029) 
de cada componente de uma dimensão; ii) a todos os componentes de uma dimensão; e iii) a cada uma das seis dimensões que compõem o índice.

\subsection{O ÍNDICE DE DESENVOLVIMENTO DA FAMÍLIA - IDF}

O IDF foi criado por Barros et al. em 2003, no qual sua proposta é ser um indicador sintético de pobreza. Ele se baseia num sistema de ponderação similar ao utilizado no IDH, entretanto, Barros et al. (2003) buscou superar as deficiências apresentadas no IDH, e a principal delas é a agregabilidade, que se refere a unidade mínima de análise para a qual se pode obter indicador sintético.

O índice segundo Barros et. al. (2003), é composto por 6 dimensões que se desdobram em 26 componentes, constituídos de 48 indicadores socioeconômicos. As seis dimensões são: a) ausência de vulnerabilidade, b) acesso ao conhecimento, c) acesso ao trabalho, d) disponibilidade de recurso, e) desenvolvimento infantil e f) condições habitacionais, quadro 1.

Quadro 1 - Dimensões, componentes e indicadores do IDF

\begin{tabular}{|c|c|}
\hline \multicolumn{2}{|r|}{ Indicadores de ausência de vulnerabilidade das famílias } \\
\hline \multirow{2}{*}{ Fecundidade } & V1. Nenhuma mulher teve filho nascido vivo no último ano \\
\hline & V2. Nenhuma mulher teve filho nascido vivo nos últimos dois anos \\
\hline \multirow{3}{*}{$\begin{array}{l}\text { Atenção e cuidados especiais } \\
\text { com crianças, adolescentes e } \\
\text { jovens }\end{array}$} & V3. Ausência de criança \\
\hline & V4. Ausência de criança ou adolescente \\
\hline & V5.Ausência de criança, adolescente ou jovem \\
\hline $\begin{array}{l}\text { Atenção e cuidados especiais } \\
\text { com idosos }\end{array}$ & V6. Ausência de idoso \\
\hline \multirow{2}{*}{ Dependência econômica } & V7. Presença de cônjuge \\
\hline & V8. Mais da metade dos membros encontram-se em idade ativa \\
\hline \multirow{2}{*}{ Presença da mãe } & V9. Não existe criança no domicílio cuja a mãe tenha morrido \\
\hline & V10. Não existe criança no domicílio que não viva com a mãe \\
\hline \multicolumn{2}{|r|}{ Indicadores de acesso ao conhecimento } \\
\hline \multirow{2}{*}{ Analfabetismo } & C1. Ausência de adulto analfabeto \\
\hline & C2. Ausência de adulto analfabeto funcional \\
\hline \multirow{3}{*}{ Escolaridade } & C3. Presença de pelo menos um adulto com fundamental completo \\
\hline & C4. Presença de pelo menos um adulto com ensino médio completo \\
\hline & C5. Presença de pelo menos um adulto com alguma educação superior \\
\hline Qualificação profissional & C6. Presença de pelo menos um trabalhador com qualificação média ou alta \\
\hline \multicolumn{2}{|r|}{ Indicadores de acesso ao trabalho } \\
\hline \multirow[b]{2}{*}{ Disponibilidade de trabalho } & T1. Mais da metade dos membros em idade ativa encontra-se ocupada \\
\hline & $\begin{array}{l}\text { T2. Presença de pelo menos um trabalhador há mais de seis meses no trabalho } \\
\text { atual }\end{array}$ \\
\hline Qualidade do posto de trabalho & T3. Presença de pelo menos um ocupado no setor formal \\
\hline
\end{tabular}

DRd - Desenvolvimento Regional em debate (ISSNe 2237-9029) 


\begin{tabular}{|c|c|}
\hline & T4. Presença de pelo menos um ocupado em atividade não-agrícola \\
\hline \multirow{2}{*}{ Remuneração } & $\begin{array}{l}\text { T5. Presença de pelo menos um ocupado com rendimento superior a } 1 \text { salário } \\
\text { mínimo }\end{array}$ \\
\hline & $\begin{array}{l}\text { T6. Presença de pelo menos um ocupado com rendimento superior a } 2 \\
\text { salários mínimos }\end{array}$ \\
\hline \multicolumn{2}{|r|}{ Indicadores de disponibilidade de recursos } \\
\hline Extrema pobreza & R1. Renda familiar per capita superior à linha de extrema pobreza \\
\hline Pobreza & R2. Renda familiar per capita superior à linha de pobreza \\
\hline Capacidade de geração de renda & R3. Maior parte da renda familiar não advém de transferência \\
\hline \multicolumn{2}{|r|}{ Indicadores de desenvolvimento infantil } \\
\hline \multirow{2}{*}{ Trabalho precoce } & D1. Ausência de criança com menos de 14 anos trabalhando \\
\hline & D2. Ausência de criança com menos de 16 anos trabalhando \\
\hline \multirow{3}{*}{ Acesso a escola } & D3. Ausência de criança até 6 anos fora da escola \\
\hline & D4. Ausência de criança até 7-14 anos fora da escola \\
\hline & D5. Ausência de criança até 7-17 anos fora da escola \\
\hline \multirow{3}{*}{ Progresso escolar } & D6. Ausência de criança de até 14 anos com mais de 2 anos de atraso \\
\hline & D7. Ausência de adolescente de 10 a 14 anos analfabeto \\
\hline & D8. Ausência de jovem de 15 a 17 anos analfabeto \\
\hline \multirow{3}{*}{ Mortalidade infantil } & D9. Ausência de mãe cujo filho tenha morrido \\
\hline & D10. Há, no máximo, uma mãe cujo filho tenha morrido \\
\hline & D11. Ausência de mãe com filho nascido morto. \\
\hline \multicolumn{2}{|r|}{ Indicadores de condições habitacionais } \\
\hline \multirow{2}{*}{ Propriedade } & H1. Domicílio próprio \\
\hline & H2. Domicílio próprio ou cedido \\
\hline Déficit & H3. Densidade de até 2 moradores por domicílio \\
\hline Abrigabilidade & H4. Material de construção permanente \\
\hline Acesso a abastecimento de água & H5. Acesso adequado a água \\
\hline Acesso a saneamento & H6. Esgotamento sanitário adequado \\
\hline Acesso a coleta de lixo & H7. Lixo é coletado \\
\hline Acesso a energia elétrica & H8. Acesso a eletricidade \\
\hline \multirow{4}{*}{ Acesso a bens duráveis } & H9. Acesso a fogão e geladeira \\
\hline & H10. Acesso a fogão, geladeira, televisão ou rádio \\
\hline & H11. Acesso a fogão, geladeira, televisão ou rádio e telefone \\
\hline & H12. Acesso a fogão, geladeira, televisão ou rádio, telefone e computador \\
\hline
\end{tabular}

Fonte: Barros et al. (2003).

De acordo com Barros et al. (2003), as dimensões acesso ao conhecimento e acesso ao trabalho são consideradas como meios para o desenvolvimento, enquanto as dimensões disponibilidade de recursos, desenvolvimento infantil e condições habitacionais são consideradas fins para o desenvolvimento. A dimensão ausência de vulnerabilidade das famílias é a única dimensão que não representa nem meios, nem fins.

O IDF é calculado para cada família, no qual as respostas só podem ser "sim" ou "não" para cada um dos 48 indicadores. Cada "sim" representa uma pontuação positiva e cada 
"não" uma pontuação negativa. O resultado deste questionário resultará no IDF, que poderá variar entre zero (pior situação possível) e um (melhor situação possível).

\subsection{METODOLOGIA PARA O CÁLCULO DO IDF}

$\mathrm{Na}$ construção de um indicador sintético, fica mais fácil sintetizar todas as informações de diversos indicadores básicos em um único número. Existem inúmeras estratégias para a construção de indicadores sintéticos. Uma possibilidade, consagrada pelo IDH [ver UNDP (2002, p. 252-253)], é obter o indicador sintético S a partir de uma série de indicadores básicos, $\{\mathrm{Bi}: \mathrm{i}=1, \ldots, \mathrm{m}\}$, através de:

$$
S=\Sigma_{i} w_{i}\left\{\frac{B_{i}-l_{i}}{L_{i}-l_{i}}\right\}
$$

Onde $L_{i}$ e $l_{i}$ são, respectivamente, o limite superior e inferior para o indicador $i$, e $w_{i}$, opeso dado a esse indicador.

Dessa forma, admitindo que cada indicador varia entre 0 e 1 , o indicador sintético fica definido a partir dos indicadores básicos através da seguinte equação:

$$
S=(1 / 6) \Sigma_{k}\left(1 / m_{k}\right) \cdot \Sigma_{j}\left(1 / n_{j k}\right) \cdot \Sigma_{i} B_{i j k}
$$

onde denota o $i$-ésimo indicador básico do $j$-ésimo componente da $k$-ésima dimensão, o número de componentes da $k$-ésima dimensão, e o número de indicadores do $j$-ésimo componente da $k$-ésima dimensão. Dessa equação temos imediatamente que:

$$
S=\Sigma_{k} \Sigma_{j}\left(1 /\left(6 m_{k} \cdot n_{j k}\right)\right) \cdot \Sigma_{i} B_{i j k}
$$

e portanto, que:

$$
w_{i j k}=\frac{1}{6 m_{k} \cdot n_{j k}}
$$

Dessa forma, conforme a equação acima, indicadores básicos de componentes distintos terminam, em geral, tendo pesos também distintos, pois o número de indicadores por componentes e número de componentes por dimensão não são homogêneos. Neste sentindo, o peso de um indicador dependerá do componente e da dimensão a que pertence.

De maneira implícita, pode-se obter indicadores sintéticos para cada um dos componentes de cada dimensão, $S_{j k}$, assim como para cada uma das dimensões, $S_{k}$, por meio de: 


$$
S_{j k}=\left(1 / n_{j k}\right) \cdot \Sigma_{j} B_{i j k}
$$

e:

$$
S_{k}=\left(1 / m_{k}\right) \cdot \Sigma_{j} S_{j k}=\left(1 / m_{k}\right) \cdot \Sigma_{j}\left(1 / n_{j k}\right) \cdot \Sigma_{i} B_{i j k}
$$

Têm-se também que:

$$
S=(1 / 6) \cdot \Sigma_{k} S_{k}
$$

Nesse sentido, o indicador sintético de cada componente, $S_{\mathrm{jk}}$, é a média aritmética dos indicadores utilizados para representar esse componente. Da mesma forma, o indicador sintético de cada dimensão, $S_{\mathrm{k}}$, é a média aritmética dos indicadores sintéticos dos seus componentes. Finalmente, o indicador sintético global, S, é a média aritmética dos indicadores sintéticos das seis dimensões que o compõem.

E sua classificação é definida como: IDF acima de 0,80 seriam considerados com alto nível de desenvolvimento, entre 0,50 e 0,79 com médio desenvolvimento e, finalmente, índices menores que 0,50, baixo nível de desenvolvimento (UNDP, 2010, 2011).

No entanto, devido a complexidade da região em análise, foi incorporado mais uma classificação, que englobará índices abaixo de 0,30. Índices nessa classificação serão considerados como nível de desenvolvimento muito baixo. Sendo assim, a classificação baixo nível de desenvolvimento será entre 0,31 a 0,49 , a muito baixo nível de desenvolvimento será entre 0,0 e 0,30 (UNDP, 2010, 2011, adaptado).

\section{RESULTADOS}

\subsection{AMAZÔNIA LEGAL E IDF}

A Amazônia Legal $^{5}$ é uma região estratégica para o Brasil e o mundo, pois a mesma abriga a maior floresta tropical e biodiversidade do planeta, além de provê serviços ecossistêmicos vitais ao bem-estar da humanidade e resguarda uma das maiores diversidades étnicas e culturais do mundo. E sobretudo, a região é muito importante para as perspectivas de desenvolvimento econômico do país, devido seu papel no suprimento de energia hidroelétrica, minérios, agropecuários e produtos florestais (CELENTANO et al., 2010).

O índice de desenvolvimento das famílias, mostrou que houve um crescimento no desenvolvimento das famílias da Amazônia Legal de 50\%, passando de um IDFm de 0,22 em

\footnotetext{
${ }^{5}$ A Amazônia Legal é composta pelos estados da região norte do Brasil: Acre, Amazonas, Amapá, Pará, Rondônia, Roraima e Tocantins; além do Mato Grosso e parte do Maranhão. A região ocupa 59\% do território do país e abriga 24 milhões de habitantes (12\% da população nacional).
} 
2000 para 0,33 em 2010, no entanto, esses números são classificados como baixo nível de desenvolvimento para os dois anos (Tabela 1).

Conforme se observa na tabela 1 , o crescimento foi influenciado sobretudo pela melhoria das dimensões acesso ao conhecimento e condições habitacionais, cada dimensão dessa obteve um crescimento de $550 \%$ e $114 \%$, respectivamente, de 2000 para 2010 . É interessante observar que as duas dimensões citadas obtiveram um crescimento bem maior que o índice final (IDFm), no entanto, para melhor entendimento do resultado final do índice deve-se analisar o comportamento de todas suas dimensões.

A dimensão ausência de vulnerabilidade das famílias (IAVF) apresentou uma redução de $24 \%$ (tabela 1), essa redução aconteceu devido um aumento no número de famílias sem a presença do cônjuge e com crianças vivendo sem a mãe. Todavia, a redução foi mais impactada pelo aumento no quantitativo de mulheres que tiveram filho nascido morto de 2000 para 2010.

Em relação a dimensão acesso ao conhecimento (IAC), o grande crescimento desse indicador (tabela 1) de um ano para o outro (550\%) aconteceu devido ao forte aumento no quantitativo no número de famílias com adultos apresentando ensino fundamental completo, ensino médio completo, e sobretudo ensino superior completo. Esse crescimento pode ser entendido como resultado das políticas públicas de incentivo a educação no país, que cresceram consideravelmente nos últimos anos.

Tabela 1 - Resultados do IDF e suas dimensões - Amazônia Legal - 2000 e 2010

\begin{tabular}{l|c|c|c}
\multicolumn{1}{c}{ ÍNDICES } & $\mathbf{2 0 0 0}$ & $\mathbf{2 0 1 0}$ & $\mathbf{2 0 1 0 - 2 0 0 0 ( \% )}$ \\
\hline Ausência de Vulnerabilidade das Famílias (IAVF) & 0,38 & 0,29 & -24 \\
Acesso ao Conhecimento (IAC) & 0,06 & 0,39 & 550 \\
Acesso ao Trabalho (IAT) & 0,43 & 0,52 & 21 \\
Disponibilidade de Recursos (IDR) & 0,08 & 0,14 & 75 \\
Desenvolvimento Infantil (IDI) & 0,06 & 0,02 & -67 \\
Condições Habitacionais (ICH) & 0,29 & 0,62 & 114 \\
Índice de Desenvolvimento das Famílias por Município (IDFm) & 0,22 & 0,33 & 50 \\
\hline
\end{tabular}

Fonte: Elaborado pelo autor. Informações extraídas dos microdados dos censos demográficos IBGE 2000 e 2010.

$\mathrm{Na}$ dimensão acesso ao trabalho (IAT) o crescimento foi o menor, de $21 \%$, pois o crescimento foi apenas no número de famílias com trabalhadores empregados no setor formal, no qual era de 0,43 em 2000 e passou para 0,52 em 2010 (tabela 1). Esse crescimento também é resultado das políticas de incentivo à educação no país, pois quando a população eleva seu nível de escolaridade consegue adquirir melhores empregos. No caso da Amazônia Legal o crescimento ainda é pequeno, pois a princípio o que se pode notar é que uma parcela da população migrou do setor informal para o formal, no entanto, é esperado que esse indicador continue crescendo ao longo do tempo.

No que diz respeito a dimensão disponibilidade de recursos (IDR), o crescimento foi de $75 \%$ (tabela 1). Esse crescimento se deu devido à redução de famílias vivendo abaixo da linha de pobreza e extrema pobreza. 
Em relação a dimensão desenvolvimento infantil (IDI), foi a que apresentou a pior redução, reduziu $67 \%$ de 2000 para 2010 (tabela 1). Essa redução aconteceu devido ao considerável crescimento de famílias com adolescente de 10 à 14 anos e 10 à 17 anos analfabetos.

E a última dimensão (condições habitacionais - ICH) apresentou o segundo maior crescimento, de $114 \%$ (tabela 1), isso aconteceu devido ao aumento no número de famílias que passaram a viver em domicílio próprio ou cedido de 2000 para 2010 e a densidade de moradores por dormitório ficou mais próxima de 2 .

Esse crescimento foi constatado quando aplicado o teste t-Student ${ }^{6}$ (tabela 2), no qual o valor foi de 25,35 a um grau de liberdade $755^{7}$ e intervalo de confiança de $5 \%$, para os dois períodos nos 756 municípios da Amazônia Legal. Para esse grau de liberdade e intervalo de confiança, o t tabelado ( $\mathrm{T}$ ) foi de 1,64, ou seja, o $\mathrm{t}$ calculado foi maior que o t tabelado, evidenciando a rejeição da hipótese nula (Ho), em que afirma que as médias em dois períodos são iguais. Logo, comprova-se que houve melhora no IDF da região de 2000 para 2010, medido através de seus municípios.

Tabela 2 - Teste t-Student, IDF dos municípios da Amazônia Legal - 2000 e 2010

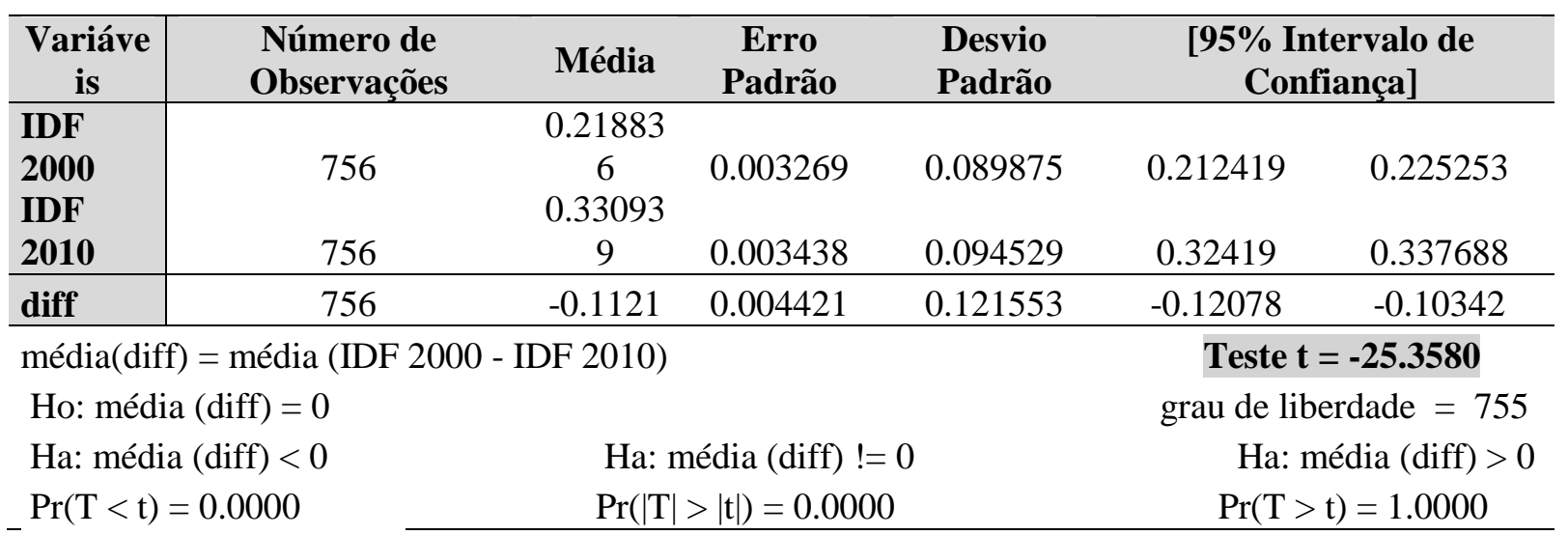

Fonte: Elaborado pelo autor.

Ho - hipótese nula; Ha - hipótese alternativa; $\operatorname{Pr}$ - valor de p; diff - diferença em diferença do estimador.

\footnotetext{
${ }^{6}$ Segundo Gujarati (2006), o teste t é um teste de hipótese que usa conceitos estatísticos para rejeitar ou não uma hipótese nula quando a estatística de teste segue uma distribuição t-Student. A hipótese nula afirma que as médias de dois períodos são iguais, e a hipótese alternativa afirma que as médias de dois períodos são diferentes.

${ }^{7}$ Grau de liberdade é o número de observações da amostra menos um, ou seja, os 756 municípios (não foi considerado os 15 municípios criados em 2010 no Mato Grosso, pois para essa análise precisa-se de amostras iguais para períodos diferentes) menos um, igual a 755 .
} 


\subsection{RESULTADOS MUNICIPAIS}

A tabela 3 apresenta um ranking dos dez maiores e dez menores IDFm da Amazônia Legal para o ano de 2000. Na tabela pode-se observar que os estados que mais apresentaram municípios com maiores IDFm foram Tocantins (quatro) e Mato Grosso (três).

No caso dos quatro municípios do Tocantins as dimensões que mais contribuíram para aumentar seus IDFm's foram a de disponibilidade de recursos e a de acesso ao trabalho. Na primeira pôde-se constatar que houve um aumento do número de famílias vivendo acima da linha de pobreza e extrema pobreza, bem como um aumento no número de famílias em que mais da metade de suas rendas não advém de transferências, ou seja, maior parte da renda familiar é advinda do trabalho.

No caso dos três municípios do Mato Grosso, duas dimensões também se destacaram para o resultado de seus IDFm's, foram a disponibilidade de recursos e a ausência de vulnerabilidade das famílias, na primeira o motivo foi exatamente o mesmo comportamento de Tocantins, explicado acima, e na segunda dimensão pôde-se constatar que a baixa presença de vulneráveis na família, como crianças, adolescentes, jovens e idosos, pode contribuir para um melhor IDF, foi o que aconteceu com os três municípios.

É relevante destacar também que o índice da dimensão disponibilidade de recursos é o que mais afeta no IDFm, pois nos dez municípios com maiores IDFm's esse indicador apresenta seu valor máximo (um), enquanto os outros não, isso é confirmado quando observase os dez menores IDFm e os mesmos apresentam valores zero para o IDR. Outro ponto importante, é o setor da economia que mais prevaleceu nos municípios com maiores IDFm's, oito dos dez municípios apresentaram o setor agropecuário mais participativo que o setor industrial, apenas Almerim (PA) e Miracema do Tocantins (TO) tiveram o setor industrial mais forte do que o setor agropecuário e o setor de serviços (IBGE, 2014).

Em uma análise comparativa entre os anos 2000 e 2010 para os dez municípios como maiores IDFm's em 2000, pôde-se observar que nenhum dos municípios classificados com maiores índices em 2000 continuaram com bons resultados em 2010. Em média os dez municípios apresentaram uma queda de 28,78\% de 2000 para 2010 (Anexo A - Tabela 5).

Vale destacar que todos os municípios apresentaram crescimento na dimensão IAC, ou pelo menos manteve seu resultado de 2000 (caso de Brejinho de Nazaré); nove dos dez também apresentaram crescimento na dimensão ICH ou manteve (apenas o município de Alvorada D'oeste apresentou queda na dimensão ICH); e o município de Arraias foi único que apresentou crescimento na dimensão IAVF.

O município de Alvorada D'Oeste (RO) foi o que apresentou a maior queda (59,79\%), saindo a $1^{\mathrm{a}}$ colocação de 2000 para a $689^{\mathrm{a}}$ em 2010, isso ocorreu porque o município apresentou queda em cinco das seis dimensões que compõe o IDF, apenas a dimensão IAC apresentou crescimento em 2010. No entanto, no que diz respeito aos aspectos macroeconômicos Alvorada D'Oeste obteve um crescimento de 39,59\% em seu PIB per capita em 2010, e uma queda de aproximadamente 50\% na pobreza e extrema pobreza (Anexo A - Tabela 5). 
Outro município que se destacou por apresentar a segunda maior queda foi Almeirim (PA), o município saiu da $8^{\mathrm{a}}$ colocação em 2000 para a $515^{\mathrm{a}}$ colocação em 2010 . Isso ocorreu porque o mesmo apresentou quedas nas dimensões IAVF, IDR e IDI. Almeirim também foi o único município, dentre os dez maiores IDFm's em 2000 que obteve um PIB per capita menor em 2010 (41,31\% menor) se comparado com 2000, isso significa que não houve crescimento econômico no município. Em relação a taxa de pobreza e extrema pobreza o município experimentou uma queda de 23,61\% em 2010 (Anexo A - Tabela 5).

Diante do exposto, apesar dos municípios que ficaram entre os dez maiores em 2000 terem apresentado queda em seus índices em 2010, os mesmos não se tornaram os piores IDFm's em 2010, e seus indicadores macroeconômicos informam que estes estão apresentam melhoras relativas em termos de crescimento econômico e qualidade de vida da população, haja vista que o nível de pobreza e extrema pobreza caiu aproximadamente $40 \%$ para os dez municípios de 2000 para 2010 , e os investimentos cresceram em saúde $(250,11 \%)$ e educação $(115,36 \%)$ em 2010 (Anexo A - Tabela 5).

Tabela 3 - Ranking dos dez maiores e menores IDFm da Amazônia Legal em 2000

\begin{tabular}{|c|c|c|c|c|c|c|c|c|}
\hline MUNICÍPIO & UF & IAVF & IAC & IAT & IDR & IDI & ICH & IDFm \\
\hline \multicolumn{9}{|c|}{10 maiores } \\
\hline Alvorada D'Oeste & RO & 0,60 & 0,28 & 0,67 & 1,00 & 0,17 & 0,57 & 0,55 \\
\hline Abreulândia & TO & 0,60 & 0,28 & 0,67 & 1,00 & 0,17 & 0,57 & 0,55 \\
\hline Jauru & MT & 0,70 & 0,28 & 0,50 & 1,00 & 0,17 & 0,43 & 0,51 \\
\hline Nova Canaã do Norte & MT & 0,53 & 0,33 & 0,50 & 1,00 & 0,17 & 0,54 & 0,51 \\
\hline Cotriguaçu & MT & 0,60 & 0,28 & 0,50 & 1,00 & 0,25 & 0,43 & 0,51 \\
\hline Brejinho de Nazaré & TO & 0,60 & 0,33 & 0,50 & 1,00 & 0,17 & 0,43 & 0,50 \\
\hline Miracema do Tocantins & TO & 0,33 & 0,28 & 0,67 & 1,00 & 0,17 & 0,57 & 0,50 \\
\hline Almeirim & PA & 0,60 & 0,33 & 0,33 & 1,00 & 0,17 & 0,57 & 0,50 \\
\hline Arraias & TO & 0,33 & 0,39 & 0,67 & 1,00 & 0,17 & 0,43 & 0,50 \\
\hline Itapuã do Oeste & RO & 0,63 & 0,28 & 0,67 & 0,67 & 0,17 & 0,57 & 0,50 \\
\hline \multicolumn{9}{|c|}{10 menores } \\
\hline Boa Vista do Ramos & $\mathrm{AM}$ & 0,30 & 0,00 & 0,00 & 0,00 & 0,00 & 0,11 & 0,07 \\
\hline São Domingos do Capim & PA & 0,30 & 0,00 & 0,00 & 0,00 & 0,00 & 0,11 & 0,07 \\
\hline Conceição do Lago-Açu & MA & 0,30 & 0,00 & 0,00 & 0,00 & 0,08 & 0,00 & 0,06 \\
\hline Envira & $\mathrm{AM}$ & 0,10 & 0,00 & 0,17 & 0,00 & 0,00 & 0,11 & 0,06 \\
\hline Penalva & MA & 0,10 & 0,00 & 0,17 & 0,00 & 0,00 & 0,11 & 0,06 \\
\hline Poconé & MT & 0,10 & 0,00 & 0,17 & 0,00 & 0,00 & 0,11 & 0,06 \\
\hline Manicoré & $\mathrm{AM}$ & 0,30 & 0,00 & 0,00 & 0,00 & 0,00 & 0,00 & 0,05 \\
\hline Cajapió & MA & 0,30 & 0,00 & 0,00 & 0,00 & 0,00 & 0,00 & 0,05 \\
\hline São Gabriel da Cachoeira & $\mathrm{AM}$ & 0,10 & 0,00 & 0,17 & 0,00 & 0,00 & 0,00 & 0,04 \\
\hline Central do Maranhão & MA & 0,10 & 0,00 & 0,00 & 0,00 & 0,00 & 0,00 & 0,02 \\
\hline
\end{tabular}

*Média do IDFm da Amazônia Legal = 0,22

Fonte: Elaborado pelo autor. Informações extraídas dos microdados dos censos demográficos IBGE 2000 e 2010.

** IAVF - Ausência de Vulnerabilidade das Famílias, IAC - Acesso ao Conhecimento, IAT - Acesso ao Trabalho, IDI - Desenvolvimento Infantil, ICH - Condições Habitacionais, e IDFm - Índice de Desenvolvimento da Família municipal. 
Ainda na tabela 3, se tratando dos dez menores IDFm compreende-se que os estados que mais apresentaram municípios em pior situação foram o Amazonas com quatro e o Maranhão também com quatro municípios. Em analise de suas dimensões, pode-se entender que o baixo acesso ao conhecimento e a baixa disponibilidade de recursos são as que mais afetam na queda do IDFm, pois nos dez municípios esses indicadores apresentam valores zero. Ou seja, o nível de escolaridade dos adultos encontram-se baixo e a incidência de pobreza e extrema pobreza ainda é relativamente grande nesses municípios, bem como a marcante presença de renda familiar advinda de transferências do governo.

Nos dez municípios com menores IDFm's 2000, pôde-se observar características em comum como: a participação dos setores no PIB de cada municípios, em que o setor de serviços é o mais participativo, e o com menor participação é o setor industrial; as principais atividades econômica que se destacaram nos municípios foram a produção agrícola, pecuária e o extrativismo; e o destino de seus recursos, em que $90 \%$ dos municípios priorizaram o investimento na educação no ano de 2000 (Anexo A - Tabela 5).

Esses dez municípios com piores resultados no IDFm em 2000 apresentaram um crescimento médio de 486,47\% no ano de 2010. Apesar dos mesmos terem continuado a apresentar IDFm's classificados como muito baixo, vale ressaltar as relativas melhoras de seus resultados, sobretudo na dimensão IAC e ICH.

Central do Maranhão também foi o município que apresentou o maior crescimento no PIB per capita no período (347,35\%), o nível de pobreza e extrema pobreza no município caíram $(28,46 \%)$. E no que diz respeito aos seus investimentos, Central do Maranhão foi o que realizou maiores investimentos em educação no ano de 2010 ( $\mathrm{R} \$ 265,40$ per capita), $160,61 \%$ a mais que em 2000. Em Manicoré o PIB per capita cresceu 105,90\%, o nível de pobreza e extrema pobreza caíram $37,44 \%$, e foi o município com maior crescimento no investimento na área de saúde $(240,74 \%)$, apesar de ter apresentado redução nos investimentos em habitação (redução de 22,12\%) (Anexo A - Tabela 5).

Sabe-se que os IDFm's desses municípios continuaram classificados como muito baixo, no entanto, vale ressaltar as relativas melhorias ocorridas após dez anos nos seus indicadores macroeconômicos associados às melhoras de seus índices desagregados (IDFm). Haja vista que houve município que conseguiu diminuir em mais de 50\% sua incidência de pobreza e extrema pobreza, foi o caso de Poconé (MT) que apresentou crescimento no IDFm de 2000 para 2010 de 429,68\% (Anexo A - Tabela 5). Isso significa que as relativas melhorias nos IDFm's desses municípios podem ser justificadas pelas melhoras em seus aspectos produtivos, além da evolução na distribuição de recursos nas subfunções municipais dos mesmos.

Em análise para o ano de 2010 (tabela 4), o estado que mais se destaque é Tocantins, pois dos 10 municípios com maiores IDFm, 7 são dele, enquanto que o Mato Grosso teve uma queda, apresentando apenas um municípios na categoria dos dez maiores. Já no quadro os dez menores IDFm, o Maranhão e o Amazonas conseguiram melhorar, pois o primeiro não apresentou mais nenhum município nessa classificação e o segundo apresentou apenas um.

Vale ressaltar, que entre os dez municípios com maiores IDFm's oito apresentaram o setor agropecuário mais participativo que o setor industrial, apenas Gurupi (TO) e Lucas do

DRd - Desenvolvimento Regional em debate (ISSNe 2237-9029) 
Rio Verde (MT) tiveram o setor industrial mais forte do que o setor agropecuário, porém o setor de serviços ainda é o mais participativo de ambos os municípios (IBGE, 2014).

Tocantins ganhou destaque por apresentar mais municípios no ranking dos dez maiores IDFm's devido o marcante peso da dimensão acesso ao conhecimento e disponibilidade de recursos. Isso significa que esses municípios apresentam mais famílias com adultos apresentando níveis de escolaridade melhores, vivendo com renda acima da linha de pobreza e extrema pobreza e com grande parte de sua renda não advinda de transferências.

Esse quantitativo de municípios para o estado de Tocantins é de se chamar atenção, pois Tocantins é a unidade federativa mais nova do Brasil ${ }^{8,}$ e segundo Oliveira (2014), é um dos estados brasileiros que tem apresentado o mais intenso processo de crescimento, tanto demográfico quanto econômico, com taxas bem superiores às médias nacionais. $\mathrm{O}$ movimento migratório, ainda em processo contínuo, torna claro que o Estado vem atraindo populações das regiões vizinhas.

O crescimento econômico e a urbanização do Tocantins de fato só começaram a acontecer a partir da década de 2000, onde seus setores produtivos passam por um processo de expansão que poderá fazer com que assuma uma posição mais relevante no cenário nacional nos próximos anos (OLIVEIRA, 2014).

Segundo IBGE (2012), a população de Tocantins teve um crescimento médio de $22,5 \%$ no período de 2000 a 2010 e em relação ao PIB, foi o Estado que mais cresceu no acumulado entre 2002 e 2010, 74,2\%. Quanto à criação de emprego formal, em 2000, o Estado contava com 106.040, em 2011, esse número passou para 242.769, um crescimento de mais $128 \%$ (MTE, 2012).

A exemplo disso, observa-se que os dois municípios com maiores crescimento no IDFm de 2000 para 2010 foram do estado de Tocantins: Bom Jesus do Tocantins e Itapiratins. O primeiro cresceu 515,08\% (como IDFm de 0,10 em 2000 para IDFm de 0,62 em 2010), passando de um nível de desenvolvimento classificado como muito baixo para um médio nível de desenvolvimento. O crescimento do PIB per capita do município foi de 30,38\% e o nível de pobreza e extrema pobreza diminuíram mais de $70 \%$. O município experimentou também significativos crescimentos no investimento em saúde $(184,42 \%)$ e habitação $(213,28 \%)$ (Anexo A - Tabela 5).

Itapiratins, segundo maior crescimento no índice em 2010, apresentou um crescimento de 291,53\% no IDFm de 2000 para 2010. O município foi o que apresentou maior crescimento no PIB per capita $(167,15 \%)$, e ficou entre os três municípios que mais apresentaram queda na taxa de pobreza e extrema pobreza $(65,38 \%)$. Em nível de investimentos, Itapiratins apresentou maiores investimentos em saúde ( $\mathrm{R}$ 295,02 per capita), seguido de educação ( $\mathrm{R}$ 248,50 per capita) (Anexo A - Tabela 5).

De modo geral, Tocantins tem experimentado relativo crescimento econômico desde a sua criação, e isso tem implicado em melhores níveis de desenvolvimento para os seus municípios, se comparado com os demais da Amazônia Legal. No entanto, vale ressaltar que os dez municípios com maiores índices em 2010 obtiveram um crescimento de 191,46\% em

\footnotetext{
${ }^{8}$ O Estado do Tocantins foi criado pela Assembleia Nacional Constituinte, no artigo 13 do Ato das Disposições Constitucionais Transitórias da Constituição da República Federativa do Brasil, promulgado em 05/10/1988.
}

DRd - Desenvolvimento Regional em debate (ISSNe 2237-9029) 
seus IDFm's de 2000 para 2010, um crescimento médio no PIB per capita de 81,72\% e uma queda de $28,32 \%$ na taxa de pobreza e extrema pobreza (Anexo A - Tabela 5). Ou seja, esses municípios, ao longo de dez anos conseguiram sair de um nível de desenvolvimento baixo ou muito baixo, para um nível de desenvolvimento médio, melhorando seus indicadores econômicos e sociais.

Tabela 4 - Ranking dos dez maiores e menores IDFm da Amazônia Legal em 2010

\begin{tabular}{|c|c|c|c|c|c|c|c|c|}
\hline MUNICÍPIO & UF & IAVF & IAC & IAT & IDR & IDI & ICH & IDFm \\
\hline \multicolumn{9}{|c|}{10 maiores } \\
\hline Bom Jesus do Tocantins & TO & 0,50 & 0,50 & 0,83 & 1,00 & 0,00 & 0,86 & 0,62 \\
\hline Divinópolis do Tocantins & TO & 0,50 & 0,50 & 0,83 & 1,00 & 0,00 & 0,86 & 0,62 \\
\hline Novo Alegre & TO & 0,50 & 0,50 & 0,83 & 1,00 & 0,00 & 0,86 & 0,62 \\
\hline Lucas do Rio Verde & MT & 0,50 & 0,50 & 0,83 & 1,00 & 0,00 & 0,86 & 0,62 \\
\hline Alto Alegre & RR & 0,50 & 0,50 & 0,83 & 1,00 & 0,08 & 0,71 & 0,61 \\
\hline Brasilândia do Tocantins & TO & 0,50 & 0,50 & 0,67 & 1,00 & 0,25 & 0,71 & 0,61 \\
\hline Campo Novo de Rondônia & RO & 0,43 & 0,50 & 0,83 & 1,00 & 0,00 & 0,86 & 0,60 \\
\hline Caseara & TO & 0,43 & 0,50 & 0,83 & 1,00 & 0,00 & 0,86 & 0,60 \\
\hline Gurupi & TO & 0,50 & 0,50 & 0,67 & 1,00 & 0,00 & 0,86 & 0,59 \\
\hline Itapiratins & TO & 0,50 & 0,50 & 0,67 & 1,00 & 0,00 & 0,86 & 0,59 \\
\hline \multicolumn{9}{|c|}{10 menores } \\
\hline Uiramutã & $\mathrm{RR}$ & 0,20 & 0,33 & 0,17 & 0,00 & 0,00 & 0,14 & 0,14 \\
\hline Cachoeira do Piriá & PA & 0,20 & 0,33 & 0,17 & 0,00 & 0,00 & 0,14 & 0,14 \\
\hline Oriximiná & $\mathrm{PA}$ & 0,20 & 0,33 & 0,17 & 0,00 & 0,00 & 0,14 & 0,14 \\
\hline São Félix do Tocantins & TO & 0,20 & 0,33 & 0,17 & 0,00 & 0,00 & 0,14 & 0,14 \\
\hline Nova Nazaré & MT & 0,20 & 0,33 & 0,17 & 0,00 & 0,00 & 0,14 & 0,14 \\
\hline Anapu & $\mathrm{PA}$ & 0,20 & 0,33 & 0,00 & 0,00 & 0,00 & 0,29 & 0,14 \\
\hline São José do Povo & MT & 0,00 & 0,33 & 0,17 & 0,00 & 0,00 & 0,29 & 0,13 \\
\hline Mazagão & AP & 0,20 & 0,33 & 0,00 & 0,00 & 0,08 & 0,14 & 0,13 \\
\hline Tarauacá & $\mathrm{AC}$ & 0,00 & 0,33 & 0,17 & 0,00 & 0,00 & 0,14 & 0,11 \\
\hline Santa Isabel do Rio Negro & $\mathrm{AM}$ & 0,00 & 0,33 & 0,17 & 0,00 & 0,00 & 0,14 & 0,11 \\
\hline
\end{tabular}

*Média do IDFm da Amazônia Legal = 0,33

Fonte: Elaborado pelo autor. Informações extraídas dos microdados dos censos demográficos IBGE 2000 e 2010.

** IAVF - Ausência de Vulnerabilidade das Famílias, IAC - Acesso ao Conhecimento, IAT - Acesso ao Trabalho, IDI - Desenvolvimento Infantil, ICH - Condições Habitacionais, e IDFm - Índice de Desenvolvimento da Família municipal.

Em análise aos dez municípios com menores IDFm's em 2010, o estado que ganhou destaque foi o Pará, apresentando três municípios nessa classificação, enquanto que em 2000 apresentava apenas um município (Tabela 4). No caso do Pará as dimensões que mais contribuíram para o baixo IDF dos municípios destacado na tabela 5 , foram a de disponibilidade de recursos e desenvolvimento infantil. 
Nove entre os dez municípios apresentaram setor de serviços mais participativo no PIB, seguido do setor agropecuário e por último ficou o setor industrial, apenas Oriximiná apresentou setor industrial mais participativo que o setor de serviços e agropecuário. No entanto, apesar disso, Oriximiná foi o município que apresentou a maior queda em seu IDFm, passando de 0,38 em 2000 para 0,14 em 2010, uma queda de 63,03\% em seu índice (Anexos A - Tabela 5). É importante destacar que o município apresentou uma pequena queda em seu PIB per capita em 2010 (5,25\%) e que sua queda na taxa de pobreza e extrema pobreza não foi tão significativa, conforme já visto em outros municípios, foi apenas 6,15\%. O município realizou maiores investimentos em educação no ano de 2010 no valor de $\mathrm{R} \$ 287,80$ per capita (Anexo A - Tabela 5).

Santa Isabel do Rio Negro no Amazonas, obteve uma queda em seu índice de 61,73\% de 2000 para 2010. As dimensões que mais caíram foram IAVF, IDR e IDI. Em análise aos seus indicadores macroeconômicos, o PIB per capita do município, ao contrário de Oriximiná, cresceu $17,82 \%$ e a taxa de pobreza e extrema pobreza apresentou um resultado menos significativo que o de Oriximiná, caiu apenas 1,64\% (Anexo A - Tabela 5).

De modo geral, mais de $80 \%$ dos municípios da Amazônia Legal experimentaram um crescimento em seus IDFm's de 2000 para 2010, apenas 15,69\% dos municípios apresentaram queda no índice.

\section{CONCLUSÃO}

Este trabalho procurou fazer uma análise sobre a pobreza e o desenvolvimento, fundamentado essencialmente na Abordagem das Capacitações de Amartya Sen, e para isso foi utilizado a medida de índice sintético para traçar o perfil socioeconômico das famílias da Amazônia Legal através da estimação do Índice de Desenvolvimento da Família - IDF.

Nos resultados do IDF da Amazônia Legal foi possível em determinadas dimensões como a IAC e ICH, se observar o efeito de uma política pública no período de dez anos (2000 e 2010). Essas duas dimensões foram as que mais elevaram o IDF, sobretudo a dimensão IAC, onde ficou claro o efeito de programas como PROJOVEM ${ }^{9}$, PROEJA $^{10}$ e o PROUNI ${ }^{11}$ na melhora da educação de milhares de famílias.

Os resultados comprovam que a Amazônia Legal é uma região que absorve as políticas públicas adotadas no país, seja ela de renda, educação, moradia e outras. Porém, em contrapartida, também sente a ausência de uma boa assistência quando o governo federal não a oferece. É o caso da dimensão IAVF, na qual o indicador de vulnerabilidade de mães com filhos nascidos mortos apresentou uma piora de 2000 para 2010, fazendo com que essa dimensão fosse a única a decrescer no período. Esse resultado demonstra que as políticas públicas federais de saúde materna ficaram aquém à esse tipo de assistência.

\footnotetext{
${ }^{9}$ Programa Nacional de Inclusão de Jovens.

${ }^{10}$ Programa de Integração da Educação Profissional ao Ensino Médio para Jovens e Adultos.

${ }^{11}$ Programa Universidade para Todos.
} 
Outro entendimento que se pode ter, enquanto a esse comportamento da região, é que a mesma é extremamente dependente das políticas públicas federais, ou seja, os governos estaduais podem está deixando muito a desejar em relação a administração de seus estados. Haja vista, que se realizassem ou melhorassem suas políticas de assistência às famílias em situação de vulnerabilidade, os indicadores teriam alcançado classificações melhores, não tendo baixo nível de desenvolvimento para os dois anos.

De modo geral, através da pesquisa foi possível localizar os municípios mais problemáticos da região, ou seja, os que merecem maiores atenções quando a aplicação de políticas públicas para sanarem suas deficiências. Pois apenas 5,96\% dos municípios da região obtiveram IDFm médio, nenhum alcançou um bom nível de desenvolvimento.

Vale ressaltar, que $82,36 \%$ dos municípios apresentaram crescimento no índice de 2000 para 2010, mesmo que $76 \%$ desses municípios tenham continuado com baixos níveis de desenvolvimento, ou seja, as famílias ainda estão sofrendo privações (pobreza multidimensional), sobretudo no que diz respeito a saúde materna (IAVF) e evasão escolar de adolescentes (IDI), seus indicadores macroeconômicos tem demonstrado que as perspectivas de crescimento para os mesmos são positivas, haja vista, que os maiores investimentos dos municípios estão sendo para educação e saúde nos últimos anos, variáveis essenciais para garantir a melhora na qualidade de vida da população.

No entanto, a importância de se analisar as características e particularidades de cada região, leva a uma observação importante, de que é relevante levantar a possibilidade da geração de um IDF mais adaptado para regiões com características particulares, como foi o caso da Amazônia Legal, que se caracterizou em grande parte como uma região de economia agropecuária.

\section{REFERÊNCIAS}

BARROS, P. A.; CARVALHO, M., FRANCO, S. Índice de desenvolvimento da família (IDF). IPEA: Rio de Janeiro, 2003. (Texto para discussão $\mathrm{N}^{\circ}$ 986).

BRASIL. Ministério da Fazenda. Finanças do Brasil: dados contábeis dos municípios - 2000 e 2010. Brasília: STN - Secretaria do Tesouro Nacional, 2010.

CELENTANO, D.; SANTOS, D.; VERÍSSIMO, A. A Amazônia e os objetivos do Milênio 2010. Belém, PA: Imazon, 2010.

CODES, A. M. M. A trajetória do pensamento científico sobre a pobreza: em direção a uma visão complexa. Brasília: IPEA, 2008. (Texto para discussão ${ }^{\circ}{ }^{1332}$ )

GUJARATI, D. Econometria básica. Rio de Janeiro: Elsevier, 2006.

HAUSMAN, D. M.; McPHERSON, M.S. Economic analysis, moral philosophy and public policy. 2.ed. New York: Cambridge University Press, 2006. 
IBGE. Instituto Brasileiro de Geografia e Estatística. IBGE Cidades: Produto Interno Bruto dos Municípios e Histórico dos Municípios (2000 e 2010). 2014. Disponível em: http://cidades.ibge.gov.br/xtras/home.php?lang= Acessado em: 13 maio 2015.

LOUREIRO, A. O. F., SULIANO, D. C. As principais linhas de pobreza utilizadas no Brasil. Instituto de Pesquisa e Estratégia Econômica do Ceará (IPECE). Nota Técnica, n. 38. ago. 2009.

PNUD. Programa das Nações Unidas para o Desenvolvimento. 2000 e 2010. Atlas do desenvolvimento humano no Brasil. Brasília: Ipea, Pnud e FJP. Disponível em: <http:// http://www.atlasbrasil.org.br/2013/pt/consulta/>. Acesso em: 10 de março 2015.

RAVALLION. M. Poverty Comparisons: A guide to concepts and methods. Washington, DC: The World Bank, 1992.

Poverty comparisons in theory and practice. Washington, DC: The World Bank. 1998 (LSMS Working Paper, n 133).

ROCHA, S. Pobreza no Brasil: afinal, de que se trata? 3.ed. Rio de Janeiro: FGV, 2006.

SEN, A. K. Poverty and famines: an essay on entitlement and deprivation. Oxford: Oxford University Press, 1981.

A Decade of Human Development. In: First Global Forum on Human Development. New York. 1999a.

Desenvolvimento como liberdade. São Paulo. Companhia das Letras, 2000.

Desigualdade reexaminada. Rio de Janeiro: Record. 2001.

UNDP (United Nations Development Programme). Human Development Report 2002. Deepening democracy in a fragmented world. Oxford University Press, Nova York. 2002.

Human development report 2010 (20th Anniversary Edition): The real wealth of nations: pathways to development human. New York: Palgrave Macmillan, 2010.

Human development report 2011: sustainability and equity: a better future for all. New York: Palgrave Macmillan, 2011. 


\section{ANEXO A}

Tabela 5 - Informações detalhadas dos 40 municípios dos rankings 2000 e 2010

(Continua)

\begin{tabular}{|c|c|c|c|c|c|c|c|c|c|c|}
\hline \multirow{2}{*}{\multicolumn{2}{|c|}{ Município }} & \multicolumn{3}{|c|}{ IDFm } & \multicolumn{3}{|c|}{ PIB per capita } & \multicolumn{3}{|c|}{ Pobreza* } \\
\hline & & 2000 & 2010 & Cresc. \% & 2000 & 2010 & Cresc. $\%$ & 2000 & 2010 & Cresc.\% \\
\hline \multirow{10}{*}{ 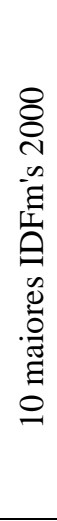 } & Alvorada D'Oeste & 0.55 & 0.22 & -59.79 & 3429.91 & 4787.79 & 39.59 & 69.78 & 35.34 & -49.36 \\
\hline & Abreulândia & 0.55 & 0.50 & -8.61 & 2505.18 & 3597.24 & 43.59 & 70.22 & 40.09 & -42.91 \\
\hline & Jauru & 0.51 & 0.36 & -29.71 & 2686.79 & 6267.12 & 133.26 & 60.58 & 31.15 & -48.58 \\
\hline & Nova Canaã do Norte & 0.51 & 0.47 & -8.11 & 2756.17 & 7019.09 & 154.67 & 38.37 & 22.37 & -41.70 \\
\hline & Cotriguaçu & 0.51 & 0.31 & -39.14 & 3067.73 & 4857.07 & 58.33 & 68.25 & 56.83 & -16.73 \\
\hline & Brejinho de Nazaré & 0.50 & 0.4 & -20.75 & 2441.69 & 5085.39 & 108.27 & 88.97 & 32.61 & -63.35 \\
\hline & Miracema do Tocantins & 0.50 & 0.36 & -28.38 & 5259.50 & 12950.96 & 146.24 & 31.66 & 25.04 & -20.91 \\
\hline & Almeirim & 0.50 & 0.29 & -42.09 & 9794.23 & 5747.80 & -41.31 & 76.93 & 58.77 & -23.61 \\
\hline & Arraias & 0.50 & 0.38 & -23.60 & 2379.16 & 6194.71 & 160.37 & 87.77 & 53.63 & -38.90 \\
\hline & Itapuã do Oeste & 0.50 & 0.36 & -27.58 & 3578.80 & 4945.37 & 38.19 & 57.53 & 26.65 & -53.68 \\
\hline \multirow{10}{*}{ 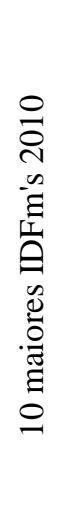 } & Bom Jesus do Tocantins & 0.10 & 0.62 & 515.08 & 1830.99 & 2387.19 & 30.38 & 107.67 & 31.61 & -70.64 \\
\hline & Divinópolis do Tocantins & 0.30 & 0.62 & 105.03 & 2376.47 & 3968.02 & 66.97 & 67.96 & 40.09 & -41.01 \\
\hline & Novo Alegre & 0.26 & 0.62 & 136.57 & 1966.68 & 3310.75 & 68.34 & 89.92 & 33.23 & -63.04 \\
\hline & Lucas do Rio Verde & 0.29 & 0.62 & 112.10 & 15547.55 & 16320.81 & 4.97 & 5.04 & 4.09 & -18.85 \\
\hline & Alto Alegre & 0.24 & 0.61 & 152.15 & 3947.48 & 4492.10 & 13.80 & 100.18 & 113.05 & 12.85 \\
\hline & Brasilândia do Tocantins & 0.21 & 0.61 & 188.17 & 2629.74 & 5147.63 & 95.75 & 70.88 & 30.10 & -57.53 \\
\hline & Campo Novo de Rondônia & 0.26 & 0.60 & 132.30 & 2414.94 & 5429.32 & 124.82 & 70.95 & 46.82 & -34.01 \\
\hline & Caseara & 0.35 & 0.60 & 72.56 & 2783.48 & 3498.03 & 25.67 & 84.43 & 43.64 & -48.31 \\
\hline & Gurupi & 0.19 & 0.59 & 209.11 & 5247.02 & 6467.50 & 23.26 & 33.05 & 8.88 & -73.13 \\
\hline & Itapiratins & 0.15 & 0.59 & 291.53 & 1747.43 & 4668.33 & 167.15 & 128.97 & 44.65 & -65.38 \\
\hline
\end{tabular}


(Continuação)

\begin{tabular}{|c|c|c|c|c|c|c|c|c|c|c|}
\hline \multirow{2}{*}{\multicolumn{2}{|c|}{ Município }} & \multicolumn{3}{|c|}{ Investimento em Saúde** } & \multicolumn{3}{|c|}{ Investimento em Educação*** } & \multicolumn{3}{|c|}{ Investimento em Habitação**** } \\
\hline & & 2000 & 2010 & Cresc. $\%$ & 2000 & 2010 & Cresc. \% & 2000 & 2010 & Cresc. \% \\
\hline \multirow{10}{*}{ 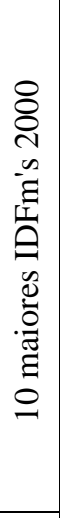 } & Alvorada D'Oeste & 74.03 & 160.73 & 117.13 & 62.67 & 192.98 & 207.93 & 5.24 & 34.58 & 559.65 \\
\hline & Abreulândia & 75.96 & 202.14 & 166.11 & 218.27 & 315.51 & 44.55 & 41.81 & 41.47 & -0.82 \\
\hline & Jauru & 53.94 & 270.16 & 400.90 & 126.33 & 177.01 & 40.12 & 0.00 & 105.62 & - \\
\hline & Nova Canaã do Norte & 50.63 & 145.72 & 187.79 & 183.95 & 202.82 & 10.26 & 0.00 & 14.83 & - \\
\hline & Cotriguaçu & 52.63 & 228.15 & 333.52 & 119.92 & 201.45 & 67.98 & 41.38 & 33.01 & -20.24 \\
\hline & Brejinho de Nazaré & 55.43 & 167.91 & 202.91 & 87.42 & 250.14 & 186.14 & 38.12 & 76.08 & 99.56 \\
\hline & Miracema do Tocantins & 38.87 & 275.92 & 609.85 & 53.00 & 159.01 & 200.01 & 38.38 & 77.62 & 102.23 \\
\hline & Almeirim & - & - & - & - & - & - & - & - & - \\
\hline & Arraias & 42.06 & 86.59 & 105.89 & 82.02 & 168.69 & 105.67 & 22.81 & 31.57 & 38.40 \\
\hline & Itapuã do Oeste & 97.94 & 222.23 & 126.90 & 107.18 & 295.35 & 175.57 & 5.86 & 0.00 & -100.00 \\
\hline \multirow{10}{*}{ 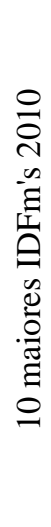 } & Bom Jesus do Tocantins & 60.78 & 172.88 & 184.42 & 111.83 & 127.91 & 14.38 & 32.36 & 101.36 & 213.28 \\
\hline & Divinópolis do Tocantins & 66.67 & 163.05 & 144.55 & 82.95 & 207.06 & 149.62 & 9.55 & 48.40 & 406.94 \\
\hline & Novo Alegre & - & 274.85 & - & - & 275.92 & - & - & 136.59 & - \\
\hline & Lucas do Rio Verde & 117.17 & 223.60 & 90.83 & 243.72 & 234.91 & -3.62 & 6.85 & 63.15 & 822.26 \\
\hline & Alto Alegre & 3.27 & 176.06 & 5276.95 & 20.68 & 172.78 & 735.32 & 22.96 & 360.62 & 1470.41 \\
\hline & Brasilândia do Tocantins & 88.98 & 283.02 & 218.09 & 211.36 & 358.02 & 69.39 & 58.83 & 101.18 & 71.98 \\
\hline & Campo Novo de Rondônia & 116.78 & 125.41 & 7.39 & 117.78 & 267.72 & 127.30 & 0.00 & 12.38 & - \\
\hline & Caseara & 72.96 & 192.51 & 163.87 & 105.40 & 187.70 & 78.09 & 87.13 & 53.49 & -38.61 \\
\hline & Gurupi & 97.28 & 25.40 & -73.89 & 73.19 & 131.04 & 79.05 & 39.51 & 147.81 & 274.16 \\
\hline & Itapiratins & 43.45 & 171.65 & 295.02 & 152.23 & 248.50 & 63.24 & 17.42 & 64.24 & 268.81 \\
\hline
\end{tabular}


(Continuação)

\begin{tabular}{|c|c|c|c|c|c|c|c|c|c|c|}
\hline \multirow{2}{*}{\multicolumn{2}{|c|}{ Município }} & \multicolumn{3}{|c|}{ IDF } & \multicolumn{3}{|c|}{ PIB per capita } & \multicolumn{3}{|c|}{ Pobreza* } \\
\hline & & 2000 & 2010 & Cresc. \% & 2000 & 2010 & Cresc. \% & 2000 & 2010 & Cresc.\% \\
\hline \multirow{10}{*}{ 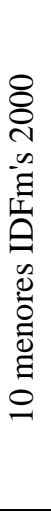 } & Boa Vista do Ramos & 0.07 & 0.31 & 356.84 & 3012.22 & 1817.14 & -39.67 & 139.13 & 101.82 & -26.82 \\
\hline & São Domingos do Capim & 0.07 & 0.20 & 194.74 & 923.25 & 1570.68 & 70.13 & 92.26 & 96.89 & 5.02 \\
\hline & Conceição do Lago-Açu & 0.06 & 0.25 & 291.30 & 1387.32 & 1740.29 & 25.44 & 135.26 & 92.01 & -31.98 \\
\hline & Envira & 0.06 & 0.26 & 317.32 & 1324.56 & 2611.49 & 97.16 & 134.33 & 93.54 & -30.37 \\
\hline & Penalva & 0.06 & 0.26 & 317.32 & 1110.32 & 1460.10 & 31.50 & 123.83 & 76.72 & -38.04 \\
\hline & Poconé & 0.06 & 0.33 & 429.68 & 2471.04 & 4451.92 & 80.16 & 66.67 & 30.51 & -54.24 \\
\hline & Manicoré & 0.05 & 0.28 & 460.00 & 1689.96 & 3479.61 & 105.90 & 118.79 & 74.31 & -37.44 \\
\hline & Cajapió & 0.05 & 0.24 & 380.00 & 982.97 & 1.227 .91 & 112.82 & 144.98 & 109.14 & -24.72 \\
\hline & São Gabriel da Cachoeira & 0.04 & 0.23 & 417.50 & 1490.46 & 2091.98 & -13.54 & 118.57 & 99.37 & -16.19 \\
\hline & Central do Maranhão & 0.02 & 0.30 & 1700.00 & 737.97 & 1288.60 & 347.35 & 126.71 & 90.65 & -28.46 \\
\hline \multirow{10}{*}{ 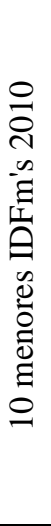 } & Uiramutã & 0.15 & 0.14 & -6.35 & 3220.38 & 3301.30 & 2.51 & 157.69 & 148.26 & -5.98 \\
\hline & Cachoeira do Piriá & 0.08 & 0.14 & 75.60 & 1035.14 & 1107.89 & 7.03 & 133.89 & 111.36 & -16.83 \\
\hline & Oriximiná & 0.38 & 0.14 & -63.03 & 9154.34 & 8674.18 & -5.25 & 77.26 & 72.51 & -6.15 \\
\hline & São Félix do Tocantins & 0.21 & 0.14 & -33.11 & 1398.46 & 2811.94 & 101.07 & 53.7 & 54.04 & 0.63 \\
\hline & Nova Nazaré & - & 0.14 & - & - & 4643.25 & - & 55.55 & 55.3 & -0.45 \\
\hline & Anapu & 0.11 & 0.14 & 24.10 & 1422.26 & 2043.99 & 43.71 & 86.09 & 71.11 & -17.40 \\
\hline & São José do Povo & 0.28 & 0.13 & -53.23 & 3013.45 & 3969.09 & 31.71 & 37.55 & 26.92 & -28.31 \\
\hline & Mazagão & 0.15 & 0.13 & -15.61 & 3179.54 & 3647.27 & 14.71 & 107.37 & 68.4 & -36.30 \\
\hline & Tarauacá & 0.15 & 0.11 & -28.57 & 2899.37 & 3680.35 & 26.94 & 116.79 & 89.35 & -23.50 \\
\hline & Santa Isabel do Rio Negro & 0.28 & 0.11 & -61.73 & 1569.79 & 1849.52 & 17.82 & 128.06 & 125.96 & -1.64 \\
\hline
\end{tabular}


(Conclusão)

\begin{tabular}{|c|c|c|c|c|c|c|c|c|c|c|}
\hline \multirow{2}{*}{\multicolumn{2}{|c|}{ Município }} & \multicolumn{3}{|c|}{ Investimento em Saúde** } & \multicolumn{3}{|c|}{ Investimento em Educação*** } & \multicolumn{3}{|c|}{ Investimento em Habitação**** } \\
\hline & & 2000 & 2010 & Cresc. \% & 2000 & 2010 & Cresc. \% & 2000 & 2010 & Cresc \% \\
\hline \multirow{10}{*}{ 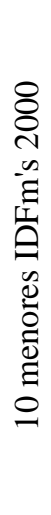 } & Boa Vista do Ramos & 69.58 & - & - & 114.90 & - & - & 22.59 & - & - \\
\hline & São Domingos do Capim & - & 58.21 & - & - & - & - & - & - & - \\
\hline & Conceição do Lago-Açu & 100.36 & - & - & 172.41 & - & - & 15.16 & - & - \\
\hline & Envira & 50.92 & 125.79 & 147.05 & 98.29 & 218.15 & 121.96 & 90.18 & 34.99 & -61.20 \\
\hline & Penalva & 62.98 & 2.90 & -95.40 & 140.67 & 23.03 & -83.63 & 0.90 & 7.47 & 734.12 \\
\hline & Poconé & 55.85 & - & - & 101.92 & - & - & 25.69 & - & - \\
\hline & Manicoré & 26.66 & 90.85 & 240.74 & 70.68 & 161.48 & 128.48 & 43.55 & 33.91 & -22.12 \\
\hline & Cajapió & 66.19 & - & - & 108.48 & - & - & 21.85 & - & - \\
\hline & São Gabriel da Cachoeira & 77.98 & 102.24 & 31.11 & 131.05 & 227.34 & 73.48 & 34.16 & 12.35 & -63.86 \\
\hline & Central do Maranhão & 55.41 & 112.25 & 102.60 & 101.84 & 265.40 & 160.61 & 25.37 & 47.12 & 85.70 \\
\hline \multirow{10}{*}{ 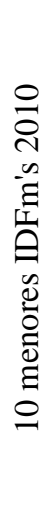 } & Uiramutã & 10.80 & 230.84 & 2037.62 & 91.26 & 209.86 & 129.95 & - & 150.45 & - \\
\hline & Cachoeira do Piriá & 25.66 & - & - & 146.32 & - & - & 69.91 & - & - \\
\hline & Oriximiná & 98.00 & 180.47 & 84.15 & 159.13 & 287.80 & 80.85 & 15.46 & 37.58 & 143.14 \\
\hline & São Félix do Tocantins & 121.12 & 272.72 & 125.16 & 122.96 & 220.25 & 79.12 & 55.21 & 291.48 & 427.90 \\
\hline & Nova Nazaré & - & 423.03 & - & - & 634.55 & - & - & 112.04 & - \\
\hline & Anapu & 0.23 & 131.12 & 58149.68 & 159.97 & 238.54 & 49.12 & 29.54 & 97.14 & 228.85 \\
\hline & São José do Povo & 276.13 & 256.11 & -7.25 & 252.98 & 219.91 & -13.08 & 3.42 & 18.16 & 430.81 \\
\hline & Mazagão & - & 112.17 & - & - & 188.16 & - & - & 16.93 & - \\
\hline & Tarauacá & 23.89 & 50.31 & 110.61 & 164.16 & 220.02 & 34.03 & 11.73 & 21.94 & 87.02 \\
\hline & Santa Isabel do Rio Negro & 70.20 & 182.66 & 160.19 & 142.07 & 168.66 & 18.71 & 45.41 & 41.13 & -9.42 \\
\hline
\end{tabular}

Fonte: IBGE, 2000 e 2010; MF-STN, 2000 e 2010; PNUD, 2000 e 2010.

* Foi somado as taxas de pobreza e extrema pobreza para esse indicador.

** Acrescido investimentos em saneamento também.

*** Acrescido investimentos em cultura também.

***** Acrescido investimentos em urbanização também.

Os valores do PIB per capita e investimentos 2010 foram deflacionados com base no ano 2000 (Deflator: 2,2217).

\section{Artigo recebido em: 01/03/2016}

\section{Artigo aprovado em: 01/06/2016}

